\title{
Autologous Lymphoid Effector Cells Specific Against Tumor Cells
}

National Cancer Institute

\section{Source}

National Cancer Institute. Autologous Lymphoid Effector Cells Specific Against Tumor

Cells. NCI Thesaurus. Code C112495.

A preparation of cytotoxic, autologous lymphoid effector cells specifically targeted towards tumor cells, with potential immunomodulating and antineoplastic activities. The autologous lymphoid effector cells are prepared by drawing a blood sample containing the required precursors for CD4+ helper T-cells, CD8+ cytotoxic T-cells, and natural killer (NK) cells from a cancer patient. The precursor cells are activated, selected and expanded to generate mature autologous lymphoid effector cells with the potential for enhanced tumor recognition. Upon readministration into the patient, the autologous lymphoid effector cells may induce both humoral and cellular immune responses against tumor cells. This may result in the immune-mediated inhibition of tumor cell proliferation, which leads to tumor cell death. 